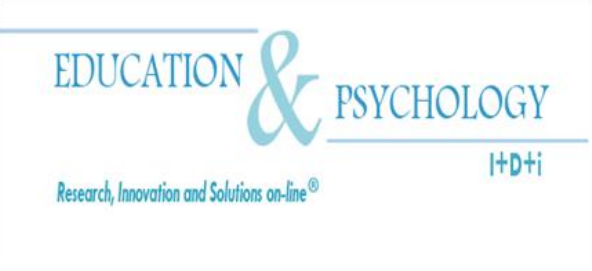

\title{
Talking about Good and Bad Learners: Linguistic Dimension of Implicit Theories of Intelligence
}

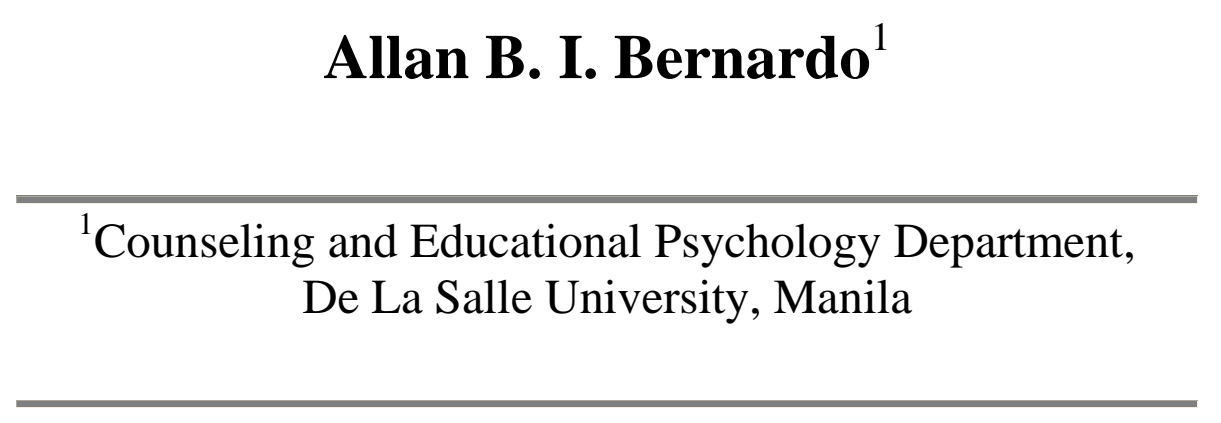

Philippines

Correspondence: Allan B. I. Bernardo, Counseling and Educational Psychology Department, Rm 1609 Br Andrew Gonzalez Hall, De La Salle University, 2401 Taft Avenue, Manila 1004 Philippines. E-mail: alan.bernardo@dlsu.edu.ph or allanbibernardo@ yahoo.com.

(C) Education \& Psychology I+D+i and Editorial EOS (Spain) 


\begin{abstract}
Introduction. Implicit theories of intelligence are lay beliefs about whether intelligence is either fixed (entity theory) or changeable (incremental theory), and are known to be important predictors of learning processes of students in schools. Four studies test the hypothesis that objectifying linguistic practices (i.e., the use of abstract linguistic categories) are associated with belief in the entity theory of intelligence, but not in incremental theory.
\end{abstract}

Method. In each study students were identified as either entity or incremental theorists, and the linguistic features of their written descriptions of good and bad learners were analyzed and compared.

Results. In all four studies, students identified as entity theorists use more nouns and adjectives but fewer verbs and contextual references in their descriptions of good and bad learners, exemplifying the objectifying linguistic practice. Students identified as incremental theorists showed the reverse pattern.

Discussion and Conclusion. The results suggest a linguistic dimension to implicit theories of intelligence. The results are discussed in terms of possible similar cognitive approaches that underlie both linguistic practices and implicit person theories of intelligence. Implications for how teachers and parents talk about their assessment of students' learning and achievement are discussed.

Keywords: implicit theories of intelligence, entity theory, incremental theory, linguistic practices, linguistic category model, Philippines 


\section{Sobre aprendices buenos y malos: la dimensión lingüística de las teorías implícitas de la inteligencia}

\section{Resumen}

Introducción. Las teorías implícitas de la inteligencia se refieren a las creencias acerca de si la inteligencia es fija (teoría de la entidad) o variable (teoría incremental), y se sabe que son importantes predictores de los procesos de aprendizaje de los estudiantes en las escuelas. Cuatro estudios probaron la hipótesis de que las prácticas de objetivación lingüística (es decir, el uso de categorías lingüísticas abstractas) se asocian con la creencia en la teoría de la entidad de inteligencia, pero no en la teoría incremental.

Método. En cada estudio se identificaron como estudiantes de cualquier entidad o teóricos adicionales, y los rasgos lingüísticos de sus descripciones escritas de los alumnos buenos y malos fueron analizados y comparados.

Resultados. En los cuatro estudios, los estudiantes identificados como los teóricos de la entidad utilizan más sustantivos y adjetivos, pero menos verbos y referencias contextuales en sus descripciones de los alumnos buenos y malos, que ejemplifica la práctica objetivación lingüística. Los estudiantes identificados como los teóricos adicionales mostraron el patrón inverso.

Discusión y Conclusiones. Los resultados sugieren una dimensión lingüística de las teorías implícitas de la inteligencia. Se discuten en términos de los posibles enfoques similares cognitivos que subyacen a ambas prácticas lingüísticas y las teorías implícitas de la persona de la inteligencia. Finalmente, se dicuten las implicaciones de cómo los profesores y los padres hablan de su evaluación de los aprendizajes de los estudiantes y los logros.

Keywords: teorías implícitas de la inteligencia, teoría de la entidad, la teoría incremental, las prácticas lingüísticas, modelo de categoría lingüística, Filipinas 


\section{Introduction}

Implicit theories of intelligence are assumptions that an individual makes about the malleability of intelligence (Dweck, 2008). Two implicit theories of intelligence have been identified: entity theory and incremental theory. Entity theory of intelligence expresses the belief that a person's intelligence is a concrete and internal quality, is fixed and stable, and cannot be changed no matter how hard one tries. On the other hand, incremental theory of intelligence expresses the belief that a person's is cultivated and can change over time, especially with effort, and are dynamic and affected by external factors. Belief in these implicit theories of intelligence has important psychological and educational consequences. For example, belief in the entity theory is associated with students' lower academic aspirations (Ahmavaara \& Houston, 2007), less use of self-regulatory learning strategies (Ommundsen, 2003), increased worrying and less practice (Cury, Da Fonseca, Hahn, \& Elliot 2008) and flat trajectories in grades over time, compared to those who believe the incremental theory, who have increasing grade trajectories (Blackwell, Trzesniewski, \& Dweck, 2007). When observing students, entity theorists are more likely to infer higher ability based on their initial performance outcomes, whereas incremental theorists are more likely to infer ability based on most recent outcomes (Butler, 2000). In this research, the linguistic dimension of the belief in these implicit theories is explored by studying students' descriptions of good and bad learners.

The way people use language is said to provide cues about their personality and other psychological functions, and various research studies have demonstrated how the use of specific types of words and other linguistic categories are associated with cognitive, social and personality variables (Pennebaker, Mehl, \& Niederhoffer, 2003; Semin, 2008). Various theories have been proposed to account for how language is associated with various aspects of human behavior. Pennebaker and King (1999) proposed that linguistic style was an individual difference variable that was a viable construct and method for understanding personality. The dimensions of linguistic style were identifying by using text analysis programs (Pennebaker, Francis, \& Booth, 2001) that identified specific linguistic cues in texts. Using such programs, research has shown how the use of specific linguistic cues are associated with a range of psychological phenomena including lying or deception (Newman, Pennebaker, Berry \& Richards, 2003), depression (Rude, Gortner, \& Pennebaker, 2004), thinking styles (Pennebaker \& Francis, 1994), and even perceptions regarding the personality and honesty of candidates for political office (Slatcher, Chung, Pennebaker, \& Stone, 2006). 
In the interpersonal domain, various studies have shown that variations in the levels of abstractness of personal descriptions reflect positive and negative perceptions of other persons (Maass, Milesi, Zabbini, \& Stahlberg, 1995; Semin, Gil de Montes, \& Valencia, 2003) and other groups (Maass, Salvi, Arcuri, \& Semin, 1989; Schnake, \& Ruscher, 1998). These subtle differences in the levels of abstractness in descriptions also affect inferences made about the target person or group (Werkman, Wigboldus, \& Semin, 1999; Wigboldus, Semin, \& Spears, 2000), and about interpersonal distance with the target (Reitsma-Van Rooijen, Semin \& Van Leeuwen, 2007). Semin (2008; Semin \& Fiedler, 1991) proposed the linguistic category model (LCM) to account for these observations. The model assumes that variation in the levels of linguistic abstraction invite different inferences about the target person or group. For example, the use of verbs, which are more concrete, invites the inference that the description of the target is time-bound and context specific. But the use of adjectives, which are more abstract, suggests that the description is more temporally enduring and generalizable across contexts; the use of nouns, which are even more abstract, implies that the description refers to a stable and general quality.

The assumptions of LCM draw from the cognitive linguistic perspective (e.g., Langacker, 1987), which states that each linguistic category implies a different construal of what it refers to. Nouns and adjectives imply object-centered descriptions, whereas state verbs and action verbs imply process-centered descriptions. Consider for example, the following example contrasting different linguistic categories used to describe a person who committed an act of saying something untrue. Describing that person by using an action verb (e.g., "he said something untrue") or a state verb (e.g., "he lied") involves a process-centered description and makes reference to some level of the context within which the specific act occurred. On the other hand, describing the person using an adjective (e.g., "he is dishonest") or a noun (e.g., "he is a liar") decontextualizes the act of saying some untruth, and instead involves an objectifying or object-centered description.

Kashima, Kashima, Kim and Gelfand (2006) drew from the LCM and proposed that people have different linguistic practices. In particular, they defined the more extensive use of nouns as adjectives as constituting objectifying linguistic practices. Objectifying linguistic practices are also decontextualized as they involve discarding contextual information in its focus on essential object qualities. In contrast, they defined the more extensive use of verbs 
as constituting contextualizing linguistic practices, which make more references to information about context, and less to the object's essential characteristics. In their study, Kashima et al. (2006) showed that cultural differences in trait ascriptions to individuals can be explained by differences in the tendency to use objectifying linguistic practices in across cultures.

Kashima et al.’s (2006) study focused on objectifying linguistic practice as a culturallevel variable. But it is first observed at the individual level, and can thus be construed as an individual difference variable that could be associated with other individual differences within a culture, similar to the approach of the other earlier studies cited. The current study takes this individual-difference approach to studying objectifying linguistic practice in accounting for students' belief in either of the two implicit theories of intelligence.

This paper reports four related studies that test the hypothesis that belief in entity theory of intelligence is positively associated with use of objectifying linguistic practices, whereas belief in incremental theory is negatively associated with the same. The reverse hypothesis can be posed regarding use of contextualizing linguistic practices. Objectifying linguistic practices reflect a cognitive focus on the actor and its attributes as an object, and are also less likely to consider contextual and other dynamic factors that may be affecting the actor. In contrast, Contextualizing linguistic practices reflect a broader cognitive focus to consider external and dynamic factors. The two are probably not mutually exclusive categories of linguistic practices. Instead, the two represent prototypical sets of linguistic behaviors, and that persons exemplify the two practices or specific aspects of the practices in different situations. In this regard, the hypothesis tested in the four studies presume that because entity theorists believe that a person's intelligence is fixed, stable, and unlikely to be affected by personal effort or external factors, entity theorists should be more likely to employ objectifying linguistic practices. In contrast, because incremental theorists believe that a person's intelligence is influenced by the dynamic interplay of personal effort and external factors, they should be less likely to employ objectifying linguistic practices. Instead, they are more likely to employ contextualizing linguistic practices, which allows them to make more references to the context in describing a person's intelligence related attributes.

The hypothesis is tested by analyzing linguistic features of students' written descriptions of good and bad learners. The students' are first classified in terms of whether they are entity or incremental theorists, and the linguistic practices apparent in their written descrip- 
tions are compared. In Study 1, the classification of the students' implicit theories was determined by analyzing the content of their written descriptions in an open-ended shortresponse task, which were then assessed in terms of the linguistic features. In Study 2a to 2c, the classification of students' implicit theories was determined using a scale developed by Chiu, Hong, and Dweck (1997). The linguistic practices were assessed using a more structured writing task. Study $2 \mathrm{a}$ to $2 \mathrm{c}$ varied in terms of the language students were told to use in their descriptions. The variable was explored because participants in the study were fluent Filipino-English bilinguals who were all very likely to code-switch and/or code-mix in their oral and written language.

In all the studies, the hypothesis was that students who are entity theorists are more likely to employ objectifying linguistic practices. Their written descriptions should use more nouns and adjectives, fewer verbs, and make fewer references to contextual information. Students who are incremental theorists are less likely to employ objectifying linguistic practices, and should thus use fewer nouns and adjectives, but more verbs and references to contextual information in their descriptions compared to their counterpart entity theorists.

\section{Study 1}

The hypothesis is first tested using data from a linguistic corpus that was part of a larger study involving a large sample of high school and college students from different parts of the Philippines.

\section{Method}

Linguistic corpus. The linguistic corpus was obtained from 695 high school and college students who were asked to describe someone who they considered to be a good learner. The question was open-ended and allowed the students to answer in whatever form they wanted. The students, all of whom were bilingual, were also told that they can answer in whatever language they want. Most students answered in English (which is the main medium for instruction in Philippine schools), and thus, much of the linguistic corpus were composed of sentences and short paragraphs in English. Some students answered in one of the Philippine languages (e.g., Filipino, Ilonggo, Cebuano), and some code-mixed. Bilingual psychology graduate students translated these responses into English. 
Participants. From the sample, two independent coders were tasked to identify respondents who provided descriptions of good learners that embodied either entity- or incremental-theory beliefs. The coders, who were blind about the hypothesis, were first given an introduction on the two implicit theories and provided a short essay contrasting the two implicit theories with an emphasis on how the theories are used to make judgments about other people. Each coder was instructed to read each participant's response and to code each complete response as either (a) an entity-theory description, (b) an incremental-theory description, or (c) unclear. Most of the complete responses were coded as unclear by both coders. From the rest of the descriptions, 50 responses that were independently coded by both as clearly expressing entity-theory descriptions and another 50 that were also independently coded as expressing incremental-theory descriptions were selected for the analysis. The 50 respondents (26 female, 24 male) in the entity-theory group were aged 11 to 20 years $(M=16.08)$. The 50 in the incremental-theory group (29 female, 21 male) were aged 12 to 20 years $(M=$ 16.20).

Coding of Responses. For each response another two independent coders determined the totals for: (a) number of words used, (b) number of nouns, (c) number of adjectives, (d) number of verbs, (e) number of sentences, and (f) number of sentences with contextual qualifications. Regarding the last item, all sentences that involved some reference to the background context (e.g., time, place, situation, condition, or other people) were considered to have contextual qualifications. The two coders came together to compare their codes, and in cases were they had different figures, they were asked to reconcile the differences so that there was $100 \%$ agreement. From this coded information, the following proportions were computed for each respondent: (a) nouns out of total words, (b) adjectives out of total words, (c) verbs out of total words, and (d) proportion of contextual sentence out of total number of sentences. The final data point computed was the objectification index (Kashima et al., 2006) that was obtained by subtracting the total number of verbs from the total number of nouns and adjectives. A larger difference indicated a higher level of objectifying linguistic practice.

\section{Results and Discussion}

There was no difference in the average number of sentences produced by the entity $(M$ $=3.46, S E=0.29)$ and incremental $(M=3.90, S E=0.32)$ groups, $F(1,98)=1.03, M S E=$ 4.68 , n.s. But the incremental group wrote more words $(M=55.70, S E=3.92)$ compared to 
the entity group $(M=41.18, S E=3.27), F(1,98)=8.09, M S E=651.70, p=.005$, so it is not safe to directly compare the number of nouns, adjectives, and verbs produced by the two groups. So the hypothesis was tested using proportion of these linguistic categories compared to the total.

Table 1. Summary statistics for Study 1

\begin{tabular}{|c|c|c|c|c|c|c|c|}
\hline \multirow{2}{*}{$\begin{array}{l}\text { Linguistic cate- } \\
\text { gory }\end{array}$} & \multicolumn{2}{|c|}{$\begin{array}{l}\text { Entity theory group } \\
\qquad(N=50)\end{array}$} & \multicolumn{2}{|c|}{$\begin{array}{l}\text { Incremental theory } \\
\text { group }(N=50)\end{array}$} & \multicolumn{3}{|c|}{$\begin{array}{l}\text { ANOVA } \\
F(1,98)\end{array}$} \\
\hline & $M$ & $S E$ & $M$ & $S E$ & $F$ & $M S E$ & $p$ \\
\hline Nouns & .029 & .005 & .012 & .002 & 9.028 & .001 & .003 \\
\hline Adjectives $^{1}$ & .092 & .019 & .035 & .006 & 8.167 & .010 & .005 \\
\hline Verbs $^{1}$ & .066 & .007 & .110 & .007 & 19.065 & .002 & .0001 \\
\hline $\begin{array}{l}\text { Objectification } \\
\text { index }^{2}\end{array}$ & .880 & .502 & -3.080 & .537 & 28.997 & 13.520 & .0001 \\
\hline $\begin{array}{l}\text { Contextualized } \\
\text { sentences }{ }^{1}\end{array}$ & .344 & .047 & .329 & .045 & 0.409 & .106 & n.s. \\
\hline
\end{tabular}

As shown in Table 1, the participants in the entity theory group were more likely to use nouns and adjectives in their descriptions compared to their counterparts in the incremental theory group. On the other hand, the participants in the incremental theory group were more likely to use verbs. These results are all consistent with the hypothesis that the use of linguistic categories associated with objectifying linguistic practices is more likely with entity theorists. The pattern of results is encapsulated in the significant difference in objectifying index scores for the two groups, where we found an average negative value for incremental theorists, and a low but positive value for entity theorists. However, the hypothesized difference regarding contextualization of sentences was not supported. The numerically higher percentage of contextualized sentences for the entity theory group was not statistically significant.

The results support the hypothesis regarding the relationship between objectifying linguistic practices and implicit theories of intelligence. However, the indicators marking the two key constructs were derived from the same data. The same sentences and paragraphs were used to determine who were entity and incremental theorists and also to assess the objectifying linguistic practices. Although independent sets of coders who were all blind about 
the hypothesis were involved in the two coding procedures, there is a need to further ensure that the indicators of implicit theories and linguistic practices are independent of each other. This concern is addressed in the next set of studies.

\section{Study 2a}

In this study, the same hypothesis was tested using a more structured linguistic task, and an independent measure of implicit theories of intelligence. To assess whether the participants were incremental or entity theorists, the implicit theories scale developed by Chiu et al. (1997) was used. To generate the linguistic corpus, the twenty statements task (TST) was modified into two ten statements tasks, following the adaptation used by Kashima et al. (2005). After identifying the two groups of participants, the linguistic features of the sentences produced were analyzed.

There were other additional design features in Study 2a. First, instead of just describing someone who they thought was a good learner, the participants were also asked to describe someone who they thought was a bad learner. Second, to ensure that the measures for the two main constructs are independent, the implicit theories scale used items that refer to the general personality of an individual. There is a version of the scale that refers to implicit theories about intelligence (Hong, Chiu, Dweck, Lin, \& Wan, 1999), and the items in that version could be construed as being associated with being a good or bad learner. On the other hand, the items in the version of the scale used referred to more general personality traits. These design features were added to allow for a stricter test of the hypothesis.

\section{Method}

Instruments. The first part of the questionnaire comprised of the two modified versions of the TST. The original TST was used to generate 20 descriptions of one's self, and used a prompt ("I am...."). In the modified version, instead of one block of 20 statements, the participants were asked to do provide two sets of ten statements. In one block, they were asked to write ten statements to describe a student who they thought was a good learner, in the other block, they were asked to write another ten statements describing someone who was a bad learner. The sequence of the blocks was counterbalanced across participants. Because the modified TST was not intended to be about one's self, the prompt was not used. An alternative prompt was not used because a similar version of the original prompt (e.g., A good learner is...) might prevent the use of verbs and/or elicit more nouns. Participants were just 
given ten numbered blank lines. They were told to answer in complete sentences, and that they could use either Filipino or English.

The modified TST was followed by the three-item implicit theories scale developed by Chiu et al. (1997). The scale is used to categorize respondents as either incremental or entity theorists. Each of the three items described a belief that human character cannot be changed. Participants were asked to indicate their extent of agreement with each item on a scale from 1 (very strongly agree) to 6 (very strongly disagree). A higher score indicates that the respondent is an incremental theorist; a lower score indicates an entity theorist. Previous research has shown good test-retest reliability of the scale (Chiu et al., 1997; Hong et al., 1999). The scale was given last to ensure that the answers did not influence the responses in the modified TST. No time limit was given for answering the entire questionnaire.

Table 2. Summary statistics for Study $2 a, 2 b$, and $2 c$

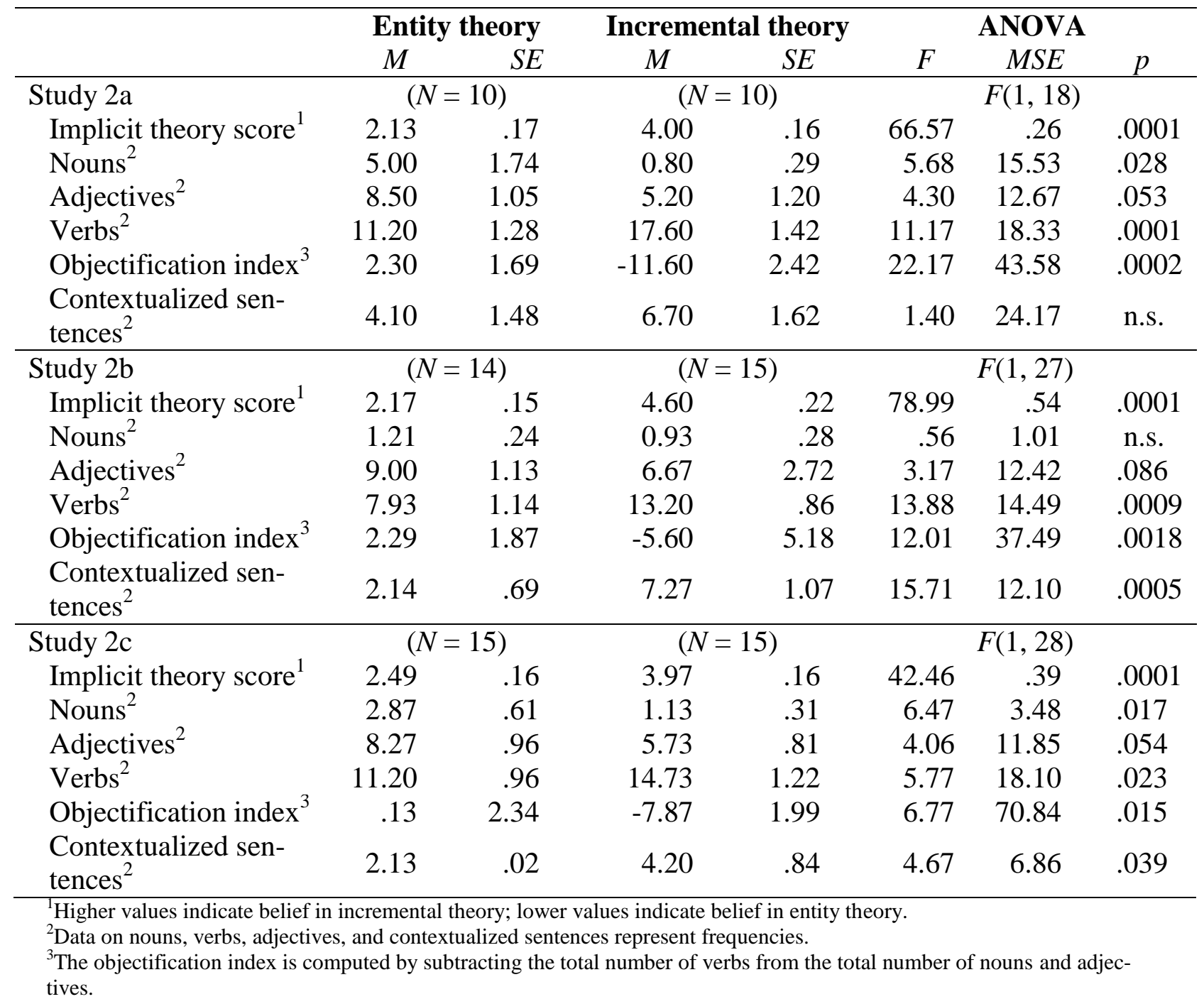


Participants. The data analyzed were from 20 university students (aged 16 to 19 years, $M=16.90$ ). Ten ( 8 females, 2 males) were identified as entity theorists based on their scores on the implicit theories scale, and ten ( 8 females, 2 males) were incremental theorists. Data from other respondents were excluded from the analysis because their responses were in the middle of the scale, and thus, did not clearly mark their implicit theory. An ANOVA of the implicit theory scores indicates that the entity theory group had lower scores compared the incremental group (see Table 2).

Coding of responses. The linguistic data were coded following the same procedure as in Study 1. Some participants did not provide ten sentences for each block, but these were still included in the analysis.

\section{Results and Discussion}

The top section of Table 2 summarizes the linguistic features of the descriptions (combining the data on descriptions of good and bad learners). The pattern of the results replicates those of Study 1. Entity theorists' descriptions used more nouns and adjectives compared to those of incremental theorists, who in turn used more verbs. The objectification indexes of the two groups were also significantly different, with the index of incremental theorists in the negative range, and that of entity theorists in the positive range. Like Study 1, there was no statistically significant difference in the number of contextualized sentences.

The results closely replicate the findings in Study 1 and provide further support for the hypothesis regarding the relationship between the objectifying linguistic practices and implicit theories of intelligence. In the studies reported thus far, Filipino-English bilingual participants were given a free choice of which language to use in their descriptions. The participants often responded in English, although some used words, phrases, and sentences in Filipino. Code-switching and code-mixing are very common in bilingual populations (Milroy \& Muysken, 1995, Wei, 2000) and are often used by Filipino students in schools (Bautista, 1991; Metila, 2009). In order to rule out the possible effects of the specific language used by the participant in writing the descriptions, two replications were conducted. 


\section{Study 2b}

This study is an exact replication of Study 2a, except that participants were all explicitly instructed to write sentences only using English.

\section{Method}

Participants. Data were from 29 university students (aged 16 to 20 years, $M=17.93$ ). Fourteen (11 females, 3 males) were identified as entity theorists, and 15 (11 females, 4 males) were incremental theorists. The entity theory group had lower implicit theory scores compared the incremental group (see Table 2).

Instruments and coding. The instruments and coding procedures in Study 2a were used; except there was an explicit instruction to use only English in writing the descriptions.

\section{Results and Discussion}

The results shown in the middle part of Table 2 show a similar pattern as those in Studies 1 and $2 b$, with some differences. The first difference was that there was no difference in the number of nouns used by the two groups. Compared to Study $2 b$, the entity group in Study $2 \mathrm{~b}$ used very few nouns. But they still used more adjectives and fewer verbs, and had a higher objectification index compared to the incremental theory group. The second difference was that the hypothesized difference in number of contextualized sentences was confirmed. The incremental theory group produced more contextualized sentence, consistent with the idea that they would use objectifying linguistic practices less.

\section{Study 2c}

This study is another exact replication of Study 2a, except that participants were all explicitly instructed to write sentences only using Filipino.

\section{Method}

Participants. Data were from 30 students (aged 16 to 19 years, $M=16.83)$. Fifteen $(9$ females, 6 males) were identified as entity theorists, and 15 (11 females, 4 males) were incremental theorists. The entity theory group had lower implicit theory scores than the incremental group (see Table 2). 
Instruments and coding. The questionnaire used in Study 2a was translated into Filipino by a bilingual research assistant and reviewed by another bilingual research assistant. The questionnaire included an explicit instruction to answer using only Filipino. The same coding procedures used in Study 2 a were used.

\section{Results and Discussion}

The results shown in the bottom part of Table 2 replicate the earlier pattern. Although in this study, all the predicted hypotheses were confirmed. The predicted difference in number of nouns used was again observed, as was the difference in number of contextualized sentences.

\section{Discussion and Conclusions}

Data from four studies show that linguistic practices of entity theorists differ from those of incremental theorists. The entity theorists in all studies used more objectifying linguistic practices (more nouns and adjectives, fewer verbs, and in some cases, less contextual references) in their written descriptions of good and bad learners. The high level of consistency across the findings could be due to the rather narrow domain of linguistic outputs examined (written descriptions of learners), which is a limitation of the study. Thus, it is important that future studies examine a wider range of linguistic behaviors involving descriptions involving other person attributes, and including oral language.

This limitation notwithstanding, the results provide evidence for the relationship between features of language and a significant aspect of human behavior that has not been previously associated with it - implicit theories of intelligence. The findings add to the growing body of evidence indicating how subtle features of everyday language seem to closely mirror specific aspects of personality-related social cognitions. In the case of objectifying linguistic practices and implicit person theories, the relationship may be mediated by similarities in cognitive focus and/or styles. The object-centered focus and decontextualized cognitive approach seem to be common features of both the objectifying linguistic practice and entity theory of intelligence (and perhaps of entity implicit theories in general); whereas, the processcentered focus and contextualized approach seem to be common to contextualized linguistic practice and incremental theory of intelligence (and also perhaps of incremental implicit theories in general). Thus, it is not unreasonable to suggest that some fundamental cognitive 
processes underlie these two aspects of behavior. However, the data in the studies cannot directly support such a proposition, nor can they be used to indicate a causal relationship between the linguistic practices and implicit person theories. Future research studies would need to include stricter experimental controls to test causal models of such relationships.

But even if the relationship between implicit person theories and linguistic practices was not established as a causal one, the consistent association shown in the four studies is noteworthy as it demonstrates a connection between two tacit aspects of human behavior. A person, more often than not, does not consciously or strategically decide which linguistic categories to use in their constructed utterances. Similarly, a person's assumptions about the malleability of person attributes are often not explicit. Yet the results show how individual differences in two seemingly separate tacit elements of behavior seem to co-vary systematically.

The findings are not only of theoretical significance; indeed, the findings point to need to look at how different agents and elements of the educational processes may be implicitly articulating and/or promoting entity or incremental theories of intelligence. Teachers' strategies in the classroom are known to influence how students make attributions about their performance in class (Tavakolizadeh \& Qavam, 2011). In this regard, teachers may be expressing their bias for incremental or entity theories of intelligence when they refer to their good or bad students in class, or when they talk about their students with other teachers or their students' parents. Parents may also be expressing such biases when talking to their children. Teachers and parents may be emphasizing one implicit theory of intelligence over another when giving feedback on the work of students or on the students' performance in school. Textbooks, learning resources and other messages within the school environment may also be implicitly promoting one implicit theory of intelligence over another.

Why is this a matter of concern? Previous research has shown that belief and either entity or incremental theories of intelligence has real consequences for students. Compared to students who believe in incremental theories of intelligence, students who hold entity theories of intelligence tend to self-handicap themselves in various ways. For example entity theorists set lower academic aspirations for themselves (Ahmavaara \& Houston, 2007), but worry more and practice less (Cury et al., 2008), and are also less likely to use the more effective selfregulatory learning strategies in class (Ommundsen, 2003). And these differences have long 
term consequences on the students' achievement; those who hold incremental theories of intelligence are known to have increasing grade trajectories over time, whereas those who hold entity theories of intelligence have flat grade trajectories (Blackwell et al., 2007). Although the present study cannot indicate a causal relationship between the linguistic description of students and belief in either entity and incremental theories of intelligence, the results of the study point to a subtle but potentially important relationship between the two that educational professional should pay attention to. Research indicates that a range of complex interrelated factors (Lozano Diaz, 2003) converge to influence the cognitions (Carpio, 2009) and motivations (Nuñez, Fontana, \& Pascual, 2011) of low achieving students, and as such it is not unlikely that how we talk about our students may actually influence how they see themselves as learners and what they strive to do as learners.

\section{References}

Ahmavaara, A., \& Houston, D. M. (2007). The effect of selective schooling and self-concept on adolescents' academic aspiration: An examination of Dweck's self-theory. British Journal of Educational Psychology, 77, 613-632.

Bautista, M. L. S. (1991). Code-switching studies in the Philippines. International Journal of the Sociology of Language, 88, 19-32.

Blackwell, L. S., Trzesniewski, K. H., \& Dweck, C. S. (2007). Implicit theories of intelligence predict achievement across an adolescent transition: A longitudinal study and an intervention. Child Development, 78, 246-263.

Butler, R. (2000). Making judgements about ability: The role of implicit theories of ability in moderating inferences from temporal and social comparison information. Journal of Personality and Social Psychology, 78, 965-978.

Carpio, H. M. (2009). Autopercepcion social y atribuciones cognotiscitivas en estudiantes de bajo rendimiento academico (Social self-perceptions and cognitive attribution in students with poor academic performance). Electronic Journal of Research in Educational Psychology, 7(3), 1175-1216.

Chiu, C.-Y., Hong, Y.-Y., \& Dweck, C. S. (1997). Lay dispositionism and implicit theories of personality. Journal of Personality and Social Psychology, 73, 19-30.

Cury, F., De Fonseca, D., Zahn, I., \& Elliot, A., (2008). Implicit theories and IQ test performance: A sequential meditational analysis. Journal of Experimental Social Psychology, 44, 783-791. 
Dweck, C. S. (2008). Can personality be changed? The role of beliefs in personality and change. Current Directions in Psychological Science, 17, 391-394.

Hong, Y. Y., Chiu, C. Y., Dweck, C. S., Lin, D. M., \& Wan, W. (1999). Implicit theories, attributions, and coping: A meaning system approach. Journal of Personality and Social Psychology, 77, 588-599.

Kashima, Y., Kashima, E. S., Kim, U., \& Gelfand, M. (2006). Describing the social world: How is a person, a group, and a relationship described in the East and the West? Journal of Experimental Social Psychology, 42, 388-396.

Lozano, A. (2003). Personal, family, and academic factors affecting low achievement in secondary school. Electronic Journal of Research in Educational Psychology, 1 (1), 43 66.

Metila, R. A. (2009). Decoding the switch: The functions of codeswitching in the classroom. Education Quarterly, 67, 44-61.

Maass, A., Milesi, A., Zabbini, S., \& Stahlberg, D. (1995). Linguistic intergroup bias: Differential expectancies or in-group protection? Journal of Personality and Social Psychology, 68, 116-126.

Milroy, L., \& Muysken, P. (1995). One speaker, two languages: Cross-disciplinary perspectives on code-switching. New York: Cambridge University Press.

Newman, M. L., Pennebaker, J. W., Berry, D. S., \& Richards, J. M. (2003). Lying words: Predicting deception from linguistic style. Personality and Social Psychology Bulletin, $29,665-675$.

Nuñez, M. C., Fontana, M., \& Pascual, I. (2011). Exploratory study of the motivational characteristics of pupils in compulsory secondary education and their relation to academic performance expectations. Electronic Journal of Research in Educational Psychology, 9, 357-382.

Ommundsen, Y. (2003). Implicit theories of ability and self-regulation strategies in physical education classes. Educational Psychology, 23, 141-157.

Pennebaker, J. W., \& King, L. A. (1999). Linguistic styles: language use as an individual difference. Journal Personality and Social Psychology, 77, 1296-312

Pennebaker, J. W., Mehl, M. R., \& Niederhoffer, K. (2003). Psychological aspects of natural language use: Our words, our selves. Annual Review of Psychology, 54, 547-577.

Reitsma-van Rooijen, M., Semin, G. R., \& van Leeuwen, E. (2007). The effects of linguistic abstraction on interpersonal distance. European Journal of Social Psychology, 37, 817-823. 
Rude, S. S., Gortner, E. M., \& Pennebaker, J. W. (2004). Language use of depressed and depression-vulnerable college students. Cognition and Emotion, 18, 1121-1133.

Schnake, S. B., \& Ruscher, J. B. (1998). Modern racism as a predictor of the linguistic intergroup bias. Journal of Language and Social Psychology, 17, 484-491.

Semin, G. R. (2008). Language puzzles: A prospective retrospective on the linguistic category model. Journal of Language and Social Psychology, 27, 197-209.

Tavakolizadeh, J., \& Qavam, S. E. (2011). Effect of teaching of self-regulated learning strategies on attribution styles in students. Electronic Journal of Research in Educational Psychology, 9, 1087-1102.

Wei, L. (2000). The bilingualism reader. New York: Routledge.

Wigboldus, D. H. J., Semin, G. R., \& Spears, R. (2000). How do we communicate stereotypes? Linguistic bases and inferential consequences. Journal of Personality and Social Psychology, 78, 5-18. 